\title{
O Livro branco da Física e da Química
}

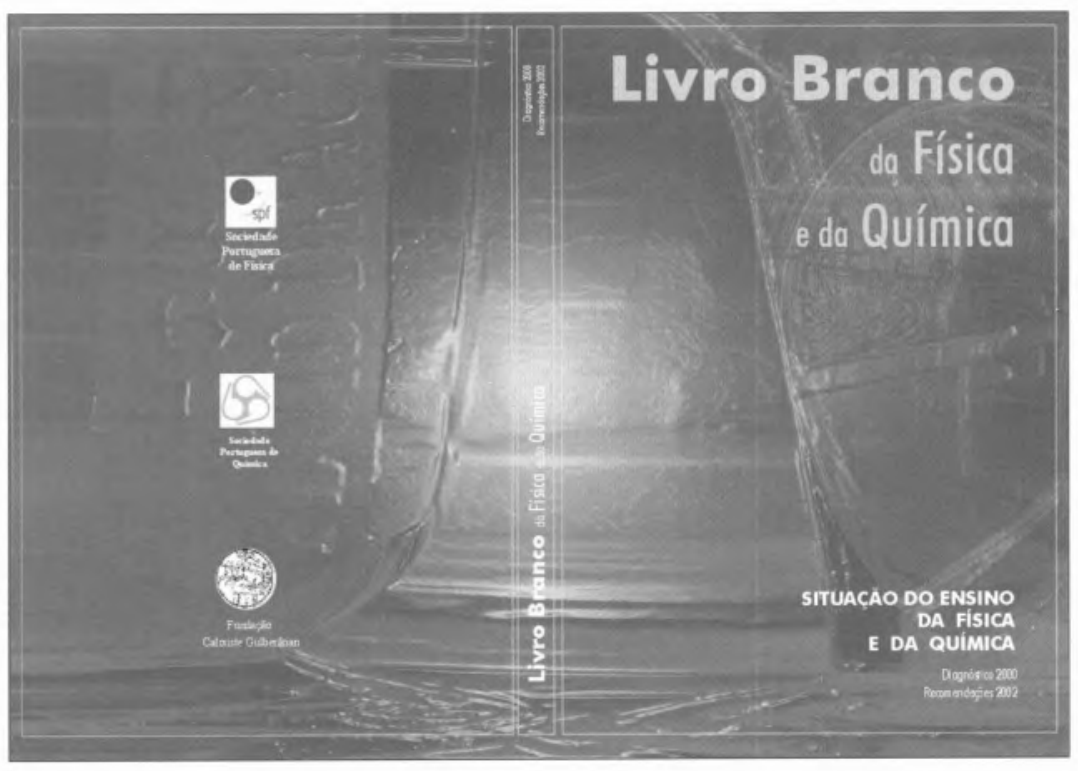

\section{Intenção que presidiu à elaboração do estudo}

Este projecto surgiu na altura do debate sobre a Revisão Curricular em curso, com a preocupação de contribuir para a identificação dos problemas que os professores de Física e Química enfrentam no ensino destas duas disciplinas e em que o insucesso dos alunos em ciências estava a ser discutido a nível mundial e no nosso país em particular.

Neste contexto, constituiu-se, na Sociedade Portuguesa de Física (SPF) e na Sociedade Portuguesa de Química (SPQ), um grupo de professores dos Ensinos Básico, Secundário e Superior, tendo em vista a finalidade de elaborar uma base de dados sobre a situação do ensino da Física e da Química e a elaboração de um diagnóstico e de um conjunto de recomendações para a meIhoria do ensino daquelas duas ciências escolares. No Livro Branco da Física e da Química descrevem-se os resultados obtidos com a aplicação de questionários e algumas recomendações para o futuro. Os questionários foram aplicados a uma amostra de 1472 professores de Física e Química, do 3. ${ }^{\circ}$ ciclo do ensino básico, do ensino secundário e do Curso Tecnológico de Química, pertencentes a 510 escolas de todo o país. Este livro foi enviado às escolas, com a finalidade de, por um lado, dar a conhecer os resultados do estudo aos professores que tão seriamente colaboraram na resposta aos questionários e, por outro, ser discutido com os professores das regiões Norte, Centro e Sul das Direcções Regionais das SPF e SPQ. O estudo abordou os seguintes aspectos relacionados com o ensino de Física e Química:

- Apreciação da situação profissional dos professores;
- Condições de trabalho na escola e nos laboratórios;

- Concepções e perspectivas sobre os programas e os trabalhos experimentais afins;

- Avaliação dos alunos e exames;

- Práticas pedagógicas e profissionais;

- Concepções e perspectivas sobre trabalho experimental;

- Necessidades de formação e motivação profissional dos professores.

Além da avaliação num plano global das principais carências e virtudes relacionadas com o ensino da Física e da Química, o livro tem também como finalidade constituir-se como uma referência que possa permitir a avaliação do grau de adequação das medidas preconizadas pela proposta de reorganização curricular, no que diz respeito à renovação do ensino das ciências. Neste contexto, - Livro Branco da Física e da Química não pode ser considerado como o fim de um trabalho, mas antes um documento referência, para iniciar e continuar no futuro um debate aprofundado centrado na análise e reflexão com todos os professores de Física e Química, com a colaboração das Sociedades Científicas, das Universidades, do Conselho Nacional de Educação, do ConseIho Nacional da Formação Contínua, das Equipas de Desenvolvimento Curricular da área das Ciências e o Ministério da Educação e o Ministério do Ensino Superior e da Ciência e Tecnologia, sem o qual não poderá ocorrer uma efectiva melhoria do ensino destas duas ciências a nível das escolas básicas e secundárias. Para que este objectivo 
seja atingido, torna-se imprescindivel que as duas sociedades cientificas, SPF e $S P Q$, desempenhem um papel mais interventivo na definiçāo de linhas orientadoras que conduzam a uma formação cientifica dos jovens, mais eficaz.

\section{Principais conclusões que se podem extrair do trabalho}

Ao longo da investigação feita durante dois anos, no âmbito do projecto Livro Branco da Física e da Química, ficou a certeza de que a problemática do ensino da Física e da Química é muito mais abrangente e complexa do que a simples análise dos resultados dos exames nacionais, da "extensão dos programas", da substituição de disciplinas ou mesmo da criação de aulas de 90 minutos. 0 sucesso de qualquer reforma de ensino, essencialmente sustentada no pressuposto de que a melhoria da formação da cultura científica da sociedade portuguesa pode ser atingida através de simples reorganizaçōes curriculares, ficará à partida comprometido se nâo forem analisadas as causas de insucessos anteriores e tomadas as medidas de resolução adequadas. Estas medidas devem ter como objectivo prioritário a elevação dos padrões de exigência e qualidade do ensino e da aprendizagem, tal como o apontam algumas conclusōes do estudo e que se descrevem a seguir.

As entidades competentes deverão reflectir sobre qual a estratégia a utilizar na definição de critérios de reconhecimento dos cursos universitários que conferem habilitaçōes próprias para o exercício da docência nos $4 .^{\circ}$ grupos $\mathrm{A}$ e B, pois cerca de $69 \%$ dos docentes tinham formação em áreas científicas (com predominância da Engenharia Química), com estágios pedagógicos e apenas $30 \%$ provinham dos Ramos Educacionais ou cursos profissionalizantes/integrados de ensino, isto é, tinham formação académica específica para o ensino da Física e da Química, apesar daqueles terem sido criados há cerca de 25 anos. Actualmente, existem aproximadamente trinta cursos universitários reconhecidos que conferem habilitação própria para o ensino da Física e
Quimica. No entanto, entre os professores deste estudo, habilitados para a docência, apenas 8\% no Ensino Básico e $11 \%$ no Secundário frequentaram cursos com formaçāo científica predominante em Física, cerca de $64 \%$ tinham uma formação predominante em Química e apenas cerca de $18 \%$ frequentaram cursos superiores cuja estrutura correspondia a uma distribuição equitativa nas áreas científicas de Fisica e Química. Sendo a maioria dos docentes (84\%) pertencentes ao $4 .{ }^{\circ}$ grupo $\mathrm{A}$, isto é, têm de ensinar Física e Quimica desde $08 .^{\circ}$ ao $11 .^{\circ}$ anos e Fisica ao $12 .{ }^{\circ}$ ano, apenas cerca de $28 \%$ destes docentes têm uma formação de base em Física e Química integradas. Estes factos podem estar na origem, por um lado, do reconhecimento de uma fraca adequação da formação académica e pedagógica às necessidades especificas do ensino, principalmente de Física e, por outro, da maior apetência evidenciada pelos estudantes pela opção predominante de disciplinas na componente técnica e de cursos, em áreas da Química, bem como um maior aproveitamento dos alunos nesta área. 0 estudo demonstrou que existe algum desfasamento entre a tipologia de acçōes de formação contínua e as necessidades de formação sentidas pelos docentes na sua prática lectiva, nomeadamente em áreas cientificas da Física e nas metodologias e didácticas especificas das duas áreas científicas.

As condições específicas para o ensino da Física e da Química nas escolas portuguesas são consideradas muito deficientes e algumas mesmo inexistentes, nomeadamente no que diz respeito a condições de segurança nos laboratórios, novas tecnologias de informação e condiçōes de manutençâo dos equipamentos. A análise efectuada sobre a apreciação da existência de laboratórios de Física e Química e respectiva qualidade, evidencia maiores carências na área da Física e, em geral, no ensino básico. Para além das deficiências quantitativas e qualitativas identificadas relativamente às condições especificas, de trabalho nas escolas, para implementação de estratégias de ensino baseadas na experimentação, os professores de
Fisica e Química deparam-se, principalmente, com um problema relacionado com os laboratórios, que condiciona negativamente a sua acçăo pedagógica: embora aqueles sejam espaços especialmente concebidos e vocacionados para aulas experimentais, a análise dos resultados evidencia que apenas cerca de $14 \%$ dos professores do ensino secundário afirma que o laboratório de Fisica é usado exclusivamente para aulas experimentais e $38 \%$ dos laboratórios de Física e cerca de $23 \%$ dos laboratórios de Química são usados para aulas de outras disciplinas. Nas escolas do ensino básico onde predomina o tipo de laboratório misto (LFQ), $61 \%$ dos professores afirmam que este também é usado para aulas de outras disciplinas e apenas cerca de $10 \%$ refere que o mesmo é usado exclusivamente para aulas experimentais. Nas, escolas secundárias com o Curso Tecnológico de Química, apenas $11 \%$ e $22 \%$ dos professores afirmam que os laboratórios de Física e de Química, respectivamente. são exclusivamente utilizados para aulas experimentais, isto é, na maioria das escolas, os laboratórios são utilizados para diversos fins, não sendo prioritariamente utilizados para aquele a que se destinam - ensino experimental da Física e da Química. Acresce o facto de que, não sendo instalações apropriadas para a leccionaçâo de aulas teóricas dispondo de bancadas de trabalho e bancos, tornam esses períodos lectivos extremamente penosos para os alunos. A situação observada pode ser entendida como uma consequência da massificação do ensino que obrigou à utilização de todas as instalações disponiveis como salas de aula normais, dada a exiguidade de instalações de algumas escolas. Trata-se efectivamente de um problema fundamental e que aparentemente só poderá ser solucionado com determinações muito específicas, por parte dos organismos competentes do Ministério da Educaçâo aos órgãos de gestão das escolas e de, simultaneamente, serem melhoradas e adaptadas as instalações laboratoriais das escolas ao número de alunos que a frequentam.

Os impactes dos Programas Ciência Viva e das disciplinas Técnicas Labora- 
toriais de Física e de Química na melhoria do equipamento das escolas e no desenvolvimento de um ensino experimental, respectivamente, foram considerados muito positivos.

O ensino da Física e da Química é caracterizado por uma abordagem essencialmente teórica e as actividades prático-experimentais são realizadas por uma minoria de cerca de $27 \%$ dos professores, essencialmente viradas para a verificação de leis, fenómenos e teorias com pouca participação activa dos alunos. As metodologias e materiais de ensino utilizados na sala de aula e na preparação das aulas são pouco diversificados, salientando-se a utilização do manual escolar e do "quadro e giz". A recolha de elementos para avaliação é feita essencialmente através de testes escritos com um peso na classificação final de cerca de $70 \%$, da observação do comportamento e envolvimento dos alunos nas aulas.

Relacionado com a aprendizagem, as maiores dificuldades dos alunos na realização de trabalho prático-experimental estão relacionadas com a formulação de hipóteses, tomada de decisões e escolha de técnicas laboratoriais de investigação, explicação de relaçōes e generalizações com base na teoria e nos resultados experimentais. Os resultados evidenciam que os professores, embora tendo uma percepção correcta sobre o papel desempenhado pelo trabalho prático-experimental na aprendizagem das ciências, não promovem nas suas aulas, em geral, actividades conducentes ao desenvolvimento de competências subjacentes à experimentação. Os principais problemas dos professores relacionados com o desenvolvimento de um ensino experimental são: falta de apoio de um técnico no laboratório, falta de laboratórios e espaços afins, falta de equipamento e/ou materiais e um baixo aproveitamento conceptual dos alunos face ao esforço despendido pelo professor.

Um aspecto apontado como causa do insucesso no ensino-aprendizagem em Física e Química relaciona-se com factores de natureza interdisciplinar. Com efeito, a preparação geral dos alunos quando chegam a um novo ciclo de es- tudos é considerada fraca e insuficiente, nomeadamente nas áreas de Matemática e Comunicação oral e escrita, interesse pelo estudo, capacidade de raciocínio e pensamento crítico, autonomia na aprendizagem, cálculo matemático e competências de resolução de problemas, parecendo não existir uma evoluçầo significativa desta situação ao longo de toda a escolaridade. No entanto, a preparação dos alunos para o prosseguimento de estudos no ensino superior é considerada adequada!

Os professores concordam que os programas são extensos, são a favor da eliminação das provas globais, da realização de exames nacionais nos $9^{\circ}, 11 .^{\circ}$ (disciplinas terminais) e $12 .^{\circ}$ anos, com a inclusão de todos os assuntos leccionados no respectivo ciclo de estudos, mas são contra os exames de trabalhos prático-experimentais a nível nacional, propondo um modelo alternativo. As principais razōes para o não cumprimento dos programas são a extensão dos mesmos, sobretudo no ensino secundário, falta de tempo, turmas grandes e heterogéneas e a falta de pré-requisitos ou de bases dos alunos. Os aspectos mais problemáticos do actual sistema de avaliação estão relacionados com dificuldades na construção e utilização de instrumentos de avaliação, sobretudo no domínio das atitudes e valores e do trabalho prático- experimental, a falta de uniformização ou aferição de critérios de avaliação e uma política educativa que promove o facilitismo, isto é, um aparente sucesso escolar preterindo a real aquisição de conhecimentos e competências.

Em suma, existe uma elevada percentagem de professores profissionalmente motivados, embora descontentes com:

- aspectos ligados à falta de condições especificas de trabalho nas escolas;

- uma gestão e organização curriculares deficientes;

- a falta de dignificação da profissão;

- a falta de apoio científico e pedagógico;

- a insuficiente formação inicial, contínua e pós graduada para o exercício da função docente
- a falta de estímulos para o envolvimento activo dos alunos numa aprendizagem autónoma movida pela curiosidade e com perfis de exigência.

Estes últimos, poderão (i) ser alguns dos factores que caracterizam a actual situação de ensino da Física e da Química e (ii) estar na base do baixo aproveitamento dos alunos nestes domínios.

\section{Principais recomendações para o futuro}

Para além do diagnóstico da situação actual do ensino da Física e da Química, em cada capítulo do relatório do Livro Branco da Física e da Química é feita uma sintese das principais conclusões e são apresentadas algumas recomendações, tendo por base a análise dos resultados obtidos no estudo.

\section{Professores}

1. Promover uma reflexão sobre o papel dos Representantes de Disciplina no apoio pedagógico aos colegas do grupo disciplinar.

2. Aprofundar conhecimentos através do acesso à informação, redes de formação, dinâmicas de grupo e realizaçâo de projectos na escola.

3. Incentivar e promover a diversificação de situações materiais na prática pedagógica, valorizando o papel do professor no desenvolvimento curricular e profissional.

4. Incentivar e promover trocas de experiências e oportunidades de formação relativas às necessidades e possibilidades de apoio pedagógico acrescido, salas de estudo acompanhado, centros de aprendizagem e de trabalho extracurricular.

\section{Promover a reflexão aprofundada} sobre estratégias de utilização do manual escolar e critérios de selecção dos mesmos, proporcionando aos professores oportunidades de formação neste domínio.

\section{Escolas/Poder central}

6. Identificar as diferentes carências, escola a escola, com vista ao equi- 
pamento e instalações experimentais com base nos resultados de estudos sobre as condiçỏes existentes.

7. Criar nas escolas, oficinas de manutenção do equipamento e criar a carreira de técnicos de apoio aos laboratórios de ciências.

8. Repensar os horários dos professores de ciências, com vista à inclusão no horário, de horas para preparação das actividades experimentais, na escola.

9. Acabar com as provas globais e criar exames no final de cada ciclo - 9. ${ }^{\circ}$ ano, $11 .^{\circ}$ ano (apenas nas disciplinas terminais, tal como as actuais Provas de Equivalência à Frequência) e $12 .^{\circ}$ ano.

10. Criar exames prático-experimentais, elaborados pelas equipas de desenvolvimento curricular, com realização centrada na escola, mas com uma contribuição para a avaliação final dos alunos.

11. Criar um Instituto de Desenvolvimento Curricular, com o objectivo de desenvolver e acompanhar de forma permanente, revisões e reformas curriculares, exames e avaliação do sistema educativo e elaboração de manuais escolares, $e$ cujos técnicos sejam seleccionados através de concursos públicos.

\section{Equipas de Desenvolvimento \\ Curricular}

12. Implementar actividades curriculares junto dos professores com a finalidade de:

(a) Aprofundar a reflexão em torno das finalidades e objectivos para o ensino da Física e da Química.

(b) Aprofundar o conhecimento das várias tendências de organização e desenvolvimento curriculares.

13. Garantir a articulação vertical e horizontal entre os programas de Física e de Química e os programas de Matemática, Biologia, Ciências da Terra e da Vida.

14. Avaliar periodicamente os resultados da implementação das inovações.

\section{Formação inicial e contínua}

A formação deve centrar-se em:

15. Reflexão sobre as funções da avaliação e formas de concretização promovendo oportunidades de formação neste domínio.

16. Metodologias e didácticas do ensino teórico-experimental, com incidência no trabalho de projecto.

17. Temas científicos relacionados com os novos programas.

18. Reestruturação da formação inicial no sentido de uma melhor qualidade e adequação ao ensino da Física e da Química nas escolas básicas e secundárias.

Lisboa, 28 de Abril de 2002

O Grupo de Trabalho do Livro Branco da Física e da Química

Doutora Anabela Martins (coordenadora), Doutora Isabel Malaquias, Doutor Décio R. Martins, Mestre Ana Carla Campos, Mestre José Manuel Lopes, Mestre Edite Maria Fiúza, Mestre Maria Manuela F. da Silva, Mestre Margarida Neves, Mestre Rolando Soares

\section{Curiosidade Pedagógica}

$A$ evolução do ensino através da evolução de um problema de matemática

\section{Ensino de 1960}

Um camponês vende um saco de batatas por 100 francos. As suas despesas elevam-se a $4 / 5$ do preço de venda.

Qual é o seu lucro?

\section{Ensino tradicional de 1970}

Um camponês vende um saco de batatas por 100 francos. As suas despesas elevam-se a $4 / 5$ do preço de venda, ou sejam 80 francos.

Qual é o seu lucro?

\section{Ensino moderno de 1970}

Um camponês troca um conjunto B de batatas por um conjunto $\mathrm{M}$ de moedas. $\mathrm{O}$ cardinal do conjunto $\mathrm{M}$ é igual a 100 e cada elemento de $\mathrm{M}$ vale 1 franco. Desenha 100 pontos que representem os elementos do conjunto $\mathrm{M}$.

O conjunto $\mathrm{C}$ dos custos de produção compreende menos 20 pontos que o conjunto M. Representa o conjunto $\mathrm{C}$ como um sub-conjunto de $\mathrm{M}$ e responde à seguinte pergunta:

Qual é o cardinal do conjunto $L$ do lucro. (escreve-o a vermelho).

\section{Ensino renovado de 1980}

Um agricultor vende um saco de batatas por 100 francos. Os custos de produção elevam-se a 80 francos e o lucro é de 20 francos.

Trabalho a realizar: Sublinha a palavra "batatas" e discute-a com o teu colega de carteira.

\section{Ensino reformado de 1990}

Um kampunês kapitalista privilejiado enriquesse injustamente em 20 francos num çaco de batatas, analiza o testo e procura os erros de kontiudo e de gramatica, de ortugrafia, de pontuassão e em ceguida dis o que penças desta maneira de enriquesser.

(Por um grupo de professores da École Normale de Grenoble, publicado na "Science et Vie"), 